Bond University

Research Repository

\title{
Acute otitis media in children presenting to the emergency department: Is it diagnosed and managed appropriately?
}

Balasundaram, Niroshan; Phan, Dung; Mazzoni, Daniel; Duong, Elliot; Sweeny, Amy; Del Mar, Chris; Keijzers, Gerben

Published in:

Journal of Paediatrics and Child Health

DOI:

10.1111/jpc. 14414

Licence:

Other

Link to output in Bond University research repository.

Recommended citation(APA):

Balasundaram, N., Phan, D., Mazzoni, D., Duong, E., Sweeny, A., Del Mar, C., \& Keijzers, G. (2019). Acute otitis media in children presenting to the emergency department: Is it diagnosed and managed appropriately? Journal of Paediatrics and Child Health, 55(11), 1335-1343. https://doi.org/10.1111/jpc.14414

\section{General rights}

Copyright and moral rights for the publications made accessible in the public portal are retained by the authors and/or other copyright owners and it is a condition of accessing publications that users recognise and abide by the legal requirements associated with these rights.

For more information, or if you believe that this document breaches copyright, please contact the Bond University research repository coordinator 


\begin{abstract}
Objectives

To describe the diagnostic and management practice in children with acute otitis media (AOM) presenting to the emergency department (ED), and compare diagnosis and management against existing guidelines.
\end{abstract}

\title{
Materials and Methods
}

We performed a retrospective descriptive cohort study of patients $\leq 15$ years of age, who presented to two EDs in Southeast Queensland between January 2016 and June 2017 with an ED diagnosis of AOM. Likelihood of diagnosis was based on medical records and classified as likely, possible or unlikely, using paediatric practice guidelines. Appropriateness of antibiotics prescription was classified by using the National Antibiotic Prescribing Survey (NAPS), which takes into account adherence to the Australian Therapeutic Guidelines (eTG). Each medical record was extracted by two blinded reviewers, and discrepancies resolved by consensus or arbitration.

\section{Results}

Of the 305 patients available for analysis, $87 \%$ had a likely or possible diagnosis of AOM. Otalgia was the presenting complaint in $75 \%$. Standard otoscopy was the routine method for tympanic membrane visualisation and $70 \%$ had abnormal tympanic membrane findings. Almost two-thirds (62\%) of all children were prescribed antibiotics. Antibiotic appropriateness could be ascertained for 286 patients(94\%). Thirty-nine percent received inappropriate antibiotic management for AOM. The majority of patients received analgesia in the form of paracetamol and/or ibuprofen.

\section{Conclusion}

ED clinicians make the diagnosis of AOM fairly accurately, although better assessment of the tympanic membrane by tympanometry and/or pneumatic otoscopy may improve accuracy. More than one-third of patients are prescribed antibiotics inappropriately. Our data can inform knowledge translation and education strategies to ensure the correct evidence-based management of this condition. 
Keywords: Acute Otitis Media, Antibiotics, Emergency Department, Paediatrics

\section{What is already known on this topic}

- $\quad$ Acute otitis media (AOM) is a common condition in infancy and childhood and a common diagnosis made in the emergency department

- $\quad$ AOM often resolves without medical intervention

- $\quad$ Inappropriate prescribing is associated with adverse drug reactions and antimicrobial resistance

\section{What this paper adds}

- This paper quantifies current practice and describes evidence-practice gaps for both diagnosis and treatment in children with an ED diagnosis of AOM

- The majority of children were prescribed antibiotics, of which more than onethird was inappropriate.

- This data can inform knowledge translation and education strategies to ensure appropriate management of AOM 


\section{Introduction}

Acute otitis media (AOM) is a common condition in infancy and childhood. Although most commonly this is a benign condition, AOM is associated with sequelae such as otorrhea, perforation of the tympanic membrane, chronic suppurative otitis media and rarely, mastoiditis. ${ }^{1}$ Episodes of AOM are associated with fluctuating mildmoderate conductive hearing loss, leading to potential deficits in language and developmental delay. ${ }^{2,3}$.

Pain and fever are common features leading to emergency department (ED) presentations. There is no gold standard for the diagnosis of AOM. Symptoms and signs used to diagnose AOM include pain, tympanic membrane bulging and fever, and confirmation of middle ear effusion is considered critical to diagnostic accuracy. ${ }^{5}$ However, the diagnosis of AOM can be challenging to make, especially when neonates or infants present with non-specific signs or symptoms, or when the tympanic membrane is difficult to visualise. Although there is no universally accepted algorithm to diagnose AOM, several guidelines exist such as the guidelines from the Royal Melbourne Children's Hospital ${ }^{6}$, the American Academy of Paediatrics guidelines ${ }^{7}$ and the Dutch general practice guidelines ${ }^{8}$. Despite this array of guidelines that can be utilised in making a diagnosis and aiding management, these need to be interpreted using the principles of evidence-based medicine and include clinical judgment. ${ }^{7}$

AOM can be viral, bacterial or combined viral-bacterial in nature and regardless of aetiology often resolves without medical intervention. ${ }^{9}$ Nevertheless, many (primary care and ED) clinicians often prescribe antibiotics for a patient with a working diagnosis of AOM. Concerns about inappropriate prescribing are fuelled by the emerging antimicrobial resistance crisis, and strategies to avoid unnecessary prescribing are needed. Some clinicians aim to avoid antibiotic use by utilising a prescribe and 'watch-and-wait' strategy, whereby an antibiotic prescription is provided with the advice to parents or carers to fill it if symptoms have not spontaneously improved within a set timeframe, usually $48 \mathrm{hrs} .{ }^{10}$ Variations in guidelines likely lead to practice variation in the decision to prescribe antibiotics, including type and duration. 
Little is known about current diagnostic and management practices in children who present to the ED and receive a diagnosis of AOM. We aimed to describe and quantify current practice and elucidate evidence-practice gaps (or guideline-practice gaps) for both diagnosis and treatment, in children with an ED diagnosis of AOM.

\section{Materials and Methods}

\section{Study design}

We conducted a retrospective, descriptive cohort study of consecutive paediatric patients with an ED diagnosis of AOM. Ethics approval was received from the Gold Coast Hospital Health Service (GCHHS) Human Research and Ethics Committee. The study reporting adheres to the STROBE statement. ${ }^{11}$

\section{Study setting and population}

We included all children up to 15 years of age who had a primary ED Information system (EDIS) diagnosis of AOM (ICD-10 AM code H66.9) over an 18-month period (1 January 2016- 1 July 2017) at two hospitals: Gold Coast University Hospital (GCUH), a tertiary facility with a dedicated children's ED, which overall had 107,000 attendance in 2017, of which 22\% were paediatric (aged under 15 years), and Robina Hospital, a general hospital with a mixed ED with 61,000 attendances in 2017 of which $16 \%$ were paediatric. Both EDs have standard otoscopes at all designated cubicles or beds, allowing direct otoscopy.

\section{Data extraction}

We extracted information on the following pre-specified data from the electronic medical record (eMR) using a data collection sheet: the Australasian Triage Scale (ATS); mode of arrival; presenting complaint; seniority of the doctor who made the diagnosis; patient demographics, clinical features; management; and disposition (whether admitted, and any referral to Ears, Nose and Throat [ENT] specialists). Two authors (any combination of NB, DM, DP and ED) extracted data independently for each patient, resolving discrepancies by consensus, or failing that, submitting the case to arbitration by a senior clinician (GK). 


\section{Classification}

The diagnostic accuracy of AOM was classified according to existing guidelines ${ }^{6-8}$ into three categories; likely, possible and unlikely (see Box 1). This classification was formulated by drawing on several available paediatric practice guidelines, including extracts from the Dutch general practice guidelines ${ }^{6}$, the American Academy of Paediatrics ${ }^{7}$ and the Royal Melbourne Children's Hospital ${ }^{8}$. The treating doctor's clinical assessment of the child's signs and symptoms, as documented in medical notes, was used to determine the likelihood category. Any patient who was deemed to have an alternative diagnosis was excluded from the analysis.

The appropriateness of antimicrobial management was assessed using the National Antibiotic Prescribing Survey (NAPS) ${ }^{12}$, which takes into account adherence to the Australian Therapeutic Guidelines (eTG, v15) ${ }^{13}$. Assessment of appropriateness was made assuming that a correct diagnosis of AOM was made. According to the eTG, all of the following conditions would be appropriate reasons for antibiotic treatment; presence of systemic features including vomiting, high-grade fever $\left(\geq 39.4^{\circ} \mathrm{C}\right)$ or lethargy; children under 6 months of age without any systemic features, but presence of discharge or bilateral AOM; background of Aboriginal or Torres Strait Islander; or AOM with symptoms persisting or worsening after two days. The level of appropriateness of antibiotic therapy was classified using four categories; optimal, adequate, suboptimal and inappropriate (see Box 2). For analysis, optimal and adequate were classed as 'appropriate' and suboptimal and inappropriate were both classed as 'inappropriate'. Specific details such as choice of antibiotic prescribed, dosage, route and duration, were all assessed before classification was made. Besides antibiotic appropriateness, whether or not pain relief was documented/given was considered. Symptomatic treatment is recommended for all cases of AOM.

\section{Data analysis}

Data are reported using descriptive statistics including proportions. Differences in diagnostic likelihood or antibiotic appropriateness proportions by patient characteristics were tested using the chi-square test or Fisher's Exact Test for small 
cells, or the chi-square test for trend, where indicated. A p-value $<.05$ was considered statistically significant.

\section{Results}

A total of 323 patients with an EDIS diagnosis of AOM were identified during the study period. Twelve were excluded for further analysis since they had a clear alternative diagnosis. An additional six children were excluded due to a lack of clinical notes recorded in the eMR (Figure 1). Overall, 305 patients were available for analysis, of which $58 \%$ were male and $25 \%(n=78)$ were under 2 years of age. The median age was 4 years [IQR 1.6-7.0]. Forty-three children (14\%) had prior ENT conditions (e.g. ventilation tubes [grommets]) with four having documented craniofacial co-morbidities.

\section{Diagnosis}

Of the 305 patients included, $27 \%$ ( $n=82)$ of patients met the criteria for a likely diagnosis of AOM, and $60 \%(n=183)$ had a possible diagnosis of AOM. About one in eight $(13 \%, n=40)$ were classified as unlikely having a diagnosis if AOM.

Table 1 describes diagnostic accuracy of AOM by clinical and process variables. Otalgia was the most common presenting complaint $(75 \%, n=228)$. Seventy percent of patients had tympanic membrane findings, including redness $(50 \%)$, bulging (23\%) and effusions or air-fluid levels (21\% combined). The remaining $30 \%$ had no abnormal tympanic membrane assessment documented either due to normal otoscopy or inability to assess the tympanic membrane. Abnormal tympanic membrane findings were more common in likely or possible AOM (Table 1). Twelve of 40 patients in whom AOM was unlikely had otorrhoea as the primary presenting complaint. The majority of patients (89\%) with previous episodes of AOM had either a likely or possible diagnosis of $A O M$. Fever $\geq 38.0^{\circ} \mathrm{C}$ was present in $21 \%$ of presentations and was significantly associated with a likely or possible diagnosis of AOM with only $9.5 \%$ of febrile children deemed unlikely to have AOM compared with $14.0 \%$ of non-febrile children $(p<.001)$. Pain relief was also more likely to be 
administered for children meeting criteria for likely or possible AOM compared to those deemed unlikely to have AOM $(90.5 \%$ vs $80.2 \%$; $p=0.002)$.

Registrar-level doctors diagnosed and managed over half $(n=171,56 \%)$ of the study population. We found no significant difference in diagnostic accuracy by seniority of the diagnosing doctor, which ranged from $76-93 \%$.

\section{Management}

When compared against Australian therapeutic guidelines using the NAPS definitions of appropriateness, antibiotic management was considered optimal in $43 \%$, adequate in $17 \%$, suboptimal in $1 \%$, and inappropriate in $39 \%$ (Figure 1). In $6 \%$ of patients, it was not possible to ascertain appropriateness of management. AOM management was more likely to be appropriate (optimal or adequate) when the child; had a fever, attended the general regional hospital, received pain relief, had a diagnosis that was likely, and did not receive antibiotics (Table 2).

Almost two-thirds $(62 \%, n=189)$ of children in this study were prescribed antibiotics, including half of those deemed unlikely to have AOM. Appropriateness could not be ascertained for nine of the 189 children; of the remaining 180 children, $47 \%$ received inappropriate antibiotics. Nearly all the inappropriate prescriptions were for children where antibiotics were not recommended by eTG. For the patients who did not receive an antibiotic prescription, $72 \%(n=76 / 105)$ were appropriately managed, as they did not meet antibiotic prescription criteria.

The most frequently prescribed antibiotic was amoxicillin (63\%), and amoxicillin/clavulanic acid was inappropriately prescribed in over half of the times when it was prescribed (19/34). The duration of antibiotic therapy was most commonly 5 days (59.3\%), or 7 days (13.2\%) (data not shown), with universally correct dosing. Twenty-three were given a prescription for an antibiotic and advised not to take them unless the child deteriorated (watch-and-wait).

For analgesia and supportive care, ibuprofen and paracetamol were the most frequently prescribed ( $46.3 \%$ and $45.6 \%$ respectively). Opioids were prescribed in 
$6.5 \%(n=20)$ of patients and topical local anaesthetic agents were rarely used $(0.3 \%)$. Children who received opioids were more likely to; have had prior AOM (45\% vs $18 \%$ ); have an effusion on otoscopy (30\% vs $15 \%$ ) and; be admitted to a ward $(10 \%$ vs $1.1 \%)$ compared to children who received simple analgesia $(n=179)$. About one-third of children received a combination of analgesic medications.

The median ED length of stay was $2.2 \mathrm{hrs}$ [IQR 1.4-3.1], and 276 (90.5\%) of children were assessed and managed within 4 hours. Length of stay was not associated with either likelihood of diagnosis or management appropriateness. Almost all children $(92.5 \%, n=283)$ were discharged home, $5.9 \%(n=18)$ were admitted to the ED shortstay unit, and $1 \%(n=3)$ were admitted to the paediatric ward. One patient was transferred out and disposition for one child was unknown. The representation rate within one-week was $4.9 \%$ and this was not associated with likelihood of diagnosis or appropriateness of antibiotics (Tables 1 and 2).

\section{Discussion}

This study evaluated diagnostic and management practices for AOM in children diagnosed in the ED. The majority $(87 \%)$ of patients had a likely or possible diagnosis of AOM, with only 1 in 8 having another diagnosis more likely. Based on the diagnostic criteria used, ED clinicians have a fair to good accuracy in making the diagnosis. An inappropriate diagnosis may invariably lead to inappropriate treatment and management.

Over one-third (39\%) of patients with a discharge diagnosis of AOM received inappropriate antibiotic management according to the NAPS classification using therapeutic guidelines. This proportion was the same if patients with an unlikely diagnosis of OAM were not taken into consideration. This high proportion of inappropriate management may reflect a potential knowledge gap, lack of experience by clinicians when dealing with such a condition, or other unmeasured variables such as (perceived) patient or parent expectation. In addition, this could also stem from a lack of understanding or utilization of guidelines by clinicians in the 
ED setting. Quach et al, ${ }^{14}$ published a retrospective analysis of physician prescribing patterns in relation to AOM. Consistent, albeit somewhat higher, they found that $47 \%$ of prescriptions given by physicians in the emergency settings were not conform with consensus guidelines.

A 2015 Cochrane review ${ }^{15}$ concluded that antibiotics have a limited role in the treatment of $\mathrm{AOM}$ in children (aged 2 months to 15 years). It emphasized that management should be focused on adequate analgesia. It further states that in high income countries, most cases of AOM spontaneously remit without complications, since many episodes of AOM are viral in etiology. In our study, almost half of antibiotic therapies were found to be inappropriate or unnecessary, suggesting there is ample room for improvement. The possible harms of antibiotic use are well known and include common patient-level adverse drug reactions including vomiting, diarrhoea and allergic reactions. These adverse events occur in one in every fourteen children given antibiotics. ${ }^{15}$ Antimicrobial resistance and health economic consequences are important at population level. ${ }^{16}$ It may be appropriate to treat AOM on a "watch-and-wait basis" in non-severe cases by withholding antibiotics, but antibiotics are encouraged to be initiated if the child's condition worsens or fails to improve within 24 to 48 hours. ${ }^{17}$ In our study this "watch-and-wait basis" approach was applied in only $7.5 \%$ of patients, suggesting this approach could be considered more frequently. Individual EDs may consider selected review of patients to encourage this approach, depending on local resources and access to alternative follow up (eg. General Practitioner).

When antibiotics are indicated, the correct antibiotic choice and duration are also important aspects of appropriate management. The most commonly used antibiotic in our two study EDs was amoxicillin (63\%) and the duration of antibiotic use was most commonly 5 days (59\%), which is consistent with Australian guidelines (eTG). Although the 5-day duration is considered standard treatment in Australia, there is ongoing debate regarding the optimal duration of treatment, with 5 days referred to as a shortened or reduced duration of treatment in the US. ${ }^{18}$

Despite this, antibiotics should be withheld in many circumstances, and appropriate pain relief management is considered the cornerstone of management in these 
cases of AOM. ${ }^{17}$ Therapeutic guidelines recommend prescribing pain relief as appropriate for all cases. In this study, one-third of children with likely or possible AOM did not have pain relief prescription documented during their ED stay. However, it is possible that the child was being adequately managed for pain at home, parents declined analgesia, or this proportion could be a reflection of suboptimal documentation. Furthermore, 20 children received opioid analgesia. This was not the first analgesic given and children received paracetamol and/or ibuprofen prior to the opioid (prior to ED arrival or in ED). Further investigation into pain management practices, including paediatric opioid stewardship, may be warranted.

\section{Limitations}

This study suffers from inherent limitations of retrospective design. However clinical records and documentation were complete and sufficient for diagnostic assessment in more than $98 \%$ of cases, and for appropriateness of management in $94 \%$, although we cannot comment on accuracy or omissions of documentation. Furthermore, our study is prone to limitations of medical record review, but we aimed to negate this bias by using two independent data extractors using a pre-formatted data collection form for each patient. Patients with AOM were selected based on the ED diagnosis, and we recognize that there are potentially missed patients with AOM who received a different diagnosis. This may have affected our accuracy of diagnosis findings but would have had little impact on our appropriateness of management findings. Visualising the tympanic membrane is important to confirm the diagnosis and was conducted with direct otoscopy in this study, reflecting the practice in our study setting. Pneumatic otoscopy provides a dynamic assessment of tympanic membrane mobility via changes in pressure, and we acknowledge that our diagnostic accuracy data may have been improved if a pneumatic otoscope or tympanometry were used for diagnosis. ${ }^{19}$ Furthermore, in absence of a gold standard for OAM, our chosen diagnostic criteria focused on symptoms moreso than signs, possibly leading to a lower threshold for making the diagnosis in symptomatic children. 
Finally, there is possibly an over-estimation of appropriate management of patients. Therapeutic guidelines do support antibiotics for children with systemic features and consistent with this, we interpreted prescription of antibiotics as 'appropriate' for children who had a documented fever or (transient) vomiting. Ideally, such scenarios would lead to a shared-decision making decision where depending on parental expectation and clinician experience a variation of choices including conservative management can be discussed.

\section{Conclusion}

ED clinicians diagnose AOM with fair to good accuracy based on the criteria used, although improved assessment of tympanic membranes by either tympanic otoscopy or tympanometry may improve accuracy further. We identified evidence-practice gaps in antibiotic prescribing, highlighting a significant proportion of children with AOM diagnosed in the ED receiving inappropriate antibiotics. Our data can inform knowledge translation, with a focus on watch-and-wait strategies and education strategies, focusing. Such initiatives are required to ensure the correct evidencebased management of this condition, ultimately improving clinical and healtheconomic outcomes. 


\section{References}

1. Abbott $P$, Gunasekera $H$, Leach AJ, et al. A multi-centre open-label randomised noninferiority trial comparing watchful waiting to antibiotic treatment for acute otitis media without perforation in low-risk urban Aboriginal and Torres Strait Islander children (the WATCH trial): study protocol for a randomised controlled trial.Trials 2016;17:119.

2. Williams CJ, Jacobs AM. The impact of otitis media on cognitive and educational outcomes. Med J Aust 2009;191(9 Suppl):S69.

3. Sibthorpe B, Agostino J, Coates H, Weeks S, Lehmann D, Wood M, et al. Indicators for continuous quality improvement for otitis media in primary health care for Aboriginal and Torres Strait Islander children. Aus J Prim Health 2017;23(1):1-9.

4. Abbott $P$, Rosenkranz $S, H u$ W, Gunasekera $H$, \& Reath J. The effect and acceptability of tympanometry and pneumatic otoscopy in general practitioner diagnosis and management of childhood ear disease. BMC Family Practice 2014; 15(181). doi: 10.1186/s12875-014-0181-x.

5. Coker TR, Chan LS, Newberry SJ, Limbos MA, Suttorp MJ, Shekelle PG, Takata GS. Diagnosis, microbial epidemiology, and antibiotic treatment of acute otitis media in children: a systematic review. JAMA. 2010;304(19):2161-9. doi: 10.1001/jama.2010.1651. Review.

6. Acute otitis media. The Royal Children's Hospital Melbourne Web Site. https://www.rch.org.au/clinicalguide/guideline index/Acute otitis media/. Updated 2017. Accessed November 25, 2017.

7. Diagnosis and management of acute otitis media. Paediatrics 2004;113(5):14511465.

8. Damoiseaux RAMJ, Venekamp RP, Eekhof JAH, et al. NHG Guidelines for General Practitioners. Utrecht, Netherlands: Bon Stafleu Van Loghum; 2014

9. Nokso-Koivisto J, Marom T, Chonmaitree T. Importance of Viruses in Acute Otitis Media. Curr Opin Pediatr 2015;27(1):110-115.

10. Isaacs D. Duration of antibiotics for acute otitis media in under 2 year olds. J Paediatr Child Health 2017;53(5):513-514.

11. STROBE statement checklist for cohort studies. STROBE statement Web Site. https://www.strobe-statement.org/index.php?id=available-checklists. Updated 2009. Accessed January 4, 2018.

12. Acute otitis media. National Antimicrobial Prescribing Survey Web site. https://www.naps.org.au. Updated 2017. Accessed on January 9, 2018.

13. Therapeutic Guidelines. Available from URL: https://www.tg.org.au Accessed on August 25, 2018.

14. Quach C, Collet JP, LeLorier J. Acute Otitis Media in children: a retrospective analysis of physician prescribing patterns. Br J Clin Pharmacol. 2004;57(4):500-505.

15. Venekamp RP, Sanders SL, Glasziou PP, Del Mar CB, Rovers MM. Antibiotics for acute otitis media in children. Cochrane Database System Rev [Internet]. 2015 [cited 2017 Nov 13]. Available from: http://onlinelibrary.wiley.com/doi/10.1002/14651858.CD000219.pub4/full.

16. Friedman ND, Temkin E, Carmeli Y. The negative impact of antibiotic resistance. Clin Microbiol Infect. 2016;22(5):416-22. 
17. Le Saux N, Robinson JL; Canadian Paediatric Society, Infectious Diseases and Immunisation Committee. Management of acute otitis media in children six months of age and older. Paediatr Child Health 2016; 21(1):39-44.

18. Hoberman A, Paradise JL, Rockette HE, Kearney DH, Bhatnagar S, Shope TR, et al. Shortened Antimicrobial Treatment for Acute Otitis Media in Young Children. N Engl J Med 2016;375(25):2446-2456.

19. Takata GS, Chan LS, Morphew T, Mangione-Smith R, Morton SC, Shekelle P. Evidence assessment of the accuracy of methods of diagnosing middle ear effusion in children with otitis media with effusion. Pediatrics. 2003;112(6 Pt 1):1379-87. Review. 
Box 1: Classification criteria for diagnosing $\mathrm{AOM}^{5,6,7}$

\section{Classification}

\section{Likely:}

a) otalgia $A N D$

b) fever/unwell $A N D$

c) at least one tympanic membrane abnormality (e.g.

Possible: bulging/red/retracted/effusion)

a) otalgia $A N D$

b) fever/unwell $O R$

c) at least one tympanic membrane abnormality

\section{Unlikely:}

a) absence of otalgia $O R$

b) otalgia with absence of both i) fever/unwell AND ii) tympanic membrane abnormality 
Box 2: Classification criteria for AOM antibiotic management appropriateness as per NAPS guidelines ${ }^{11}$

\section{Classification}

\section{Appropriate}

Inappropriate

Not able to be assessed

\section{Optimal}

Optimal antimicrobial choice/dosage/route/duration

\section{Adequate}

Non-optimal choice/dosage/route/duration, but is a reasonable alternative for the likely causative pathogen

\section{Suboptimal}

Unreasonable choice/dosage/route/duration including:

a) Spectrum excessively broad or an unnecessary overlap in spectrum of activity

b) Mild or non-life-threatening allergy mismatch

\section{Inappropriate}

Antimicrobial choice/dosage/route/duration is not indicated to treat the likely causative pathogen $O R$ An anti-microbial is not indicated for the presumed infection $O R$

There may be a severe or possible life-threatening allergy mismatch

The notes are not comprehensive enough to assess appropriateness, or

The patient is too complex, due to multiple co-morbidities, allergies or microbiology results 
Table 1. Patient and hospital characteristics by likelihood of diagnosis for acute otitis media, amongst children $<15$ years who had an emergency department

diagnosis of acute otitis media

\begin{tabular}{|c|c|c|c|c|c|c|c|c|}
\hline & \multicolumn{2}{|c|}{ Likely (n=82) } & \multicolumn{2}{|c|}{ Possible (n=183) } & \multicolumn{2}{|c|}{ Unlikely $(n=40)$} & \multicolumn{2}{|c|}{$\begin{array}{l}\text { Overall } \\
(n=305)\end{array}$} \\
\hline & $\mathbf{n}$ & $\%$ & $\mathbf{n}$ & $\%$ & $\mathbf{n}$ & $\%$ & n & $\%$ \\
\hline \multicolumn{9}{|l|}{ Age } \\
\hline$<6 \mathrm{mos}$ & 1 & 8.3 & 8 & 66.7 & 3 & 25.0 & 12 & 3.9 \\
\hline $6 \mathrm{mos}-23 \mathrm{mos}$ & 20 & 30.3 & 29 & 43.9 & 17 & 25.8 & 66 & 21.6 \\
\hline $24+\operatorname{mos}$ & 61 & 26.9 & 146 & 64.3 & 20 & 8.8 & 227 & 74.4 \\
\hline \multicolumn{9}{|l|}{ Sex } \\
\hline M & 51 & 28.7 & 104 & 58.4 & 23 & 12.9 & 178 & 58.4 \\
\hline $\mathrm{F}$ & 31 & 24.4 & 79 & 62.2 & 17 & 13.4 & 127 & 41.6 \\
\hline \multicolumn{9}{|l|}{ AOM symptoms present } \\
\hline Otalgia & 76 & 33.3 & 145 & 63.6 & 7 & 3.1 & 228 & 74.8 \\
\hline No otalgia documented & 6 & 7.8 & 38 & 49.4 & 33 & 42.9 & 77 & 25.2 \\
\hline Otorrhoea & 19 & 22.9 & 52 & 62.7 & 12 & 14.5 & 83 & 27.2 \\
\hline No otorrhoea documented & 63 & 28.4 & 131 & 59.0 & 28 & 12.6 & 222 & 72.8 \\
\hline Fever $>=38^{\circ} \mathrm{C}$ & 38 & 60.3 & 19 & 30.2 & 6 & 9.5 & 63 & 20.7 \\
\hline No fever documented & 44 & 18.2 & 164 & 67.8 & 34 & 14.0 & 242 & 79.3 \\
\hline $\begin{array}{r}\text { Any two or more of otalgia, fever } \\
\text { or otorrhea }\end{array}$ & 43 & 46.7 & 47 & 51.1 & 2 & 2.2 & 92 & 30.2 \\
\hline $\begin{array}{r}\text { Only one of: otalgia, fever, } \\
\text { otorrhea }\end{array}$ & 37 & 20.6 & 122 & 67.8 & 21 & 11.7 & 180 & 59.0 \\
\hline None of above & 2 & 6.1 & 14 & 42.4 & 17 & 51.5 & 33 & 10.8 \\
\hline \multicolumn{9}{|l|}{$\begin{array}{l}\text { Systemic features present } \\
\text { Systemic }^{\dagger} \text { and one or more }\end{array}$} \\
\hline symptoms & 15 & 25.9 & 37 & 63.8 & 6 & 10.3 & 58 & 19.0 \\
\hline Systemic $^{\dagger}$ but no symptoms & 0 & 0.0 & 3 & 33.3 & 6 & 66.7 & 9 & 3.0 \\
\hline $\begin{array}{r}\text { Not systemic but one or more } \\
\text { symptoms }\end{array}$ & 65 & 30.4 & 132 & 61.7 & 17 & 7.9 & 214 & 70.2 \\
\hline
\end{tabular}


Neither systemic nor symptoms

$$
\text { present }
$$

$$
2
$$

8.3

11

45.8

11

45.8

Tympanic membrane features

Redness

$38.2 \quad 83$

$54.6 \quad 11$

7.2

$52.1 \quad 4$

5.6

$\begin{array}{llll}\text { Ruptured } & 8 & 24.2 & 22\end{array}$

Abnormal air fluid level

$$
36.4
$$

66.7

$$
3
$$

$$
63.6
$$

0

0.0

Effusion 18

Any of above

30

$55.6 \quad 6$

11.1

$56.8 \quad 18 \quad 8.5$

Any of above, except redness

49

37.1

73

$$
55.3
$$

\begin{tabular}{|c|c|}
\hline 2 & 1 \\
\hline 3 & 58 \\
\hline $4 / 5$ & 23 \\
\hline
\end{tabular}

Triage category

$\begin{array}{rccccccccc}2 & 1 & 12.5 & 4 & 50.0 & 3 & 37.5 & 8 & 2.6 \\ 3 & 58 & 28.2 & 114 & 55.3 & 34 & 16.5 & 206 & 67.5 \\ 4 / 5 & 23 & 25.3 & 65 & 71.4 & 3 & 3.3 & 91 & 29.8 \\ & & & & & & & & \\ \text { Yes } & 21 & 30.4 & 40 & 58.0 & 8 & 11.6 & 69 & 22.6 \\ & 61 & 25.8 & 143 & 60.6 & 32 & 13.6 & 236 & 77.4 \\ \text { nown } & & & & & & & & \\ \text { ident) } & 5 & 13.2 & 25 & 65.8 & 8 & 21.1 & 38 & 12.5 \\ \text { ident } & 29 & 31.2 & 58 & 62.4 & 6 & 6.5 & 93 & 30.5 \\ \text { ultant } & 47 & 27.5 & 98 & 57.3 & 26 & 15.2 & 171 & 56.1 \\ \text { nown } & 1 & 24.1 & 15 & 51.7 & 7 & 24.1 & 29 & 9.5 \\ & & 33.3 & 2 & 66.7 & 0 & 0.0 & 3 & 1.0 \\ \text { No } & 7 & & & & & & & \\ \text { No } & 75 & 27.0 & 165 & 59.4 & 38 & 13.7 & 278 & 91.1\end{array}$

Previous acute otitis media

Yes

\section{Treating doctor level}

$$
\text { No/Unknown }
$$

Junior (intern or student)

Resident

Registrar

Consultant

21

61

Other/unknown

$5 \quad 13.2$

$29 \quad 31.2$

$47 \quad 27.5$

$7 \quad 24.1$

Hospital

Robina $\quad 30 \quad 40.5$

$\begin{array}{rrr}\text { Robina } & 30 & 40.5 \\ \text { University Hospital } & 52 & 22.5\end{array}$

\section{Watch and wait method used}

This is the peer reviewed version of the following article: Balasundaram, N., Phan, D., Mazzoni, D., Duong, E., Sweeny, A., Del Mar, C., \& Keijzers, G. (2019). Acute otitis media in children presenting to the emergency department: Is it diagnosed and managed appropriately? Journal of Paediatrics and Child Health, which has been published in final form at https://doi.org/10.1111/ipc.14414which. This article may be used for non-commercial purposes in accordance with Wiley Terms and Conditions for Use of Self-Archived Versions. 


\begin{tabular}{|c|c|c|c|c|c|c|c|c|}
\hline Not documented/unknown & 0 & 0.0 & 3 & 75.0 & 1 & 25.0 & 4 & 1.3 \\
\hline \multicolumn{9}{|l|}{ Antibiotic use } \\
\hline Yes & 57 & 30.2 & 112 & 59.3 & 20 & 10.6 & 189 & 62.0 \\
\hline No & 25 & 21.6 & 71 & 61.2 & 20 & 17.2 & 116 & 38.0 \\
\hline \multicolumn{9}{|l|}{ Analgesia use } \\
\hline Paracetamol only & 10 & 20.8 & 30 & 62.5 & 8 & 16.7 & 48 & 15.7 \\
\hline Ibuprofen only & 21 & 40.4 & 29 & 55.8 & 2 & 3.8 & 52 & 17.0 \\
\hline Opioid only & 0 & 0.0 & 6 & 100.0 & 0 & 0.0 & 6 & 2.0 \\
\hline Combination of above & 31 & 33.3 & 53 & 57.0 & 9 & 9.7 & 93 & 30.5 \\
\hline Any pain relief & 62 & 31.2 & 118 & 59.3 & 19 & 9.5 & 199 & 65.2 \\
\hline No pain relief & 20 & 18.9 & 65 & 61.3 & 21 & 19.8 & 106 & 34.8 \\
\hline \multicolumn{9}{|l|}{ Represented within one week } \\
\hline Yes & 4 & 26.7 & 7 & 46.7 & 4 & 26.7 & 15 & 4.9 \\
\hline No & 78 & 26.9 & 178 & 61.4 & 36 & 12.4 & 290 & 95.1 \\
\hline \multicolumn{9}{|l|}{ Exceeded 4 hours of stay } \\
\hline Yes & 72 & 26.1 & 168 & 60.9 & 36 & 13.0 & 276 & 90.5 \\
\hline No & 10 & 34.5 & 15 & 51.7 & 4 & 13.8 & 29 & 9.5 \\
\hline
\end{tabular}

$\dagger$ systemic: vomiting, fever $\geq 39.4$, abdominal pain 


\begin{tabular}{|c|c|c|c|c|c|c|}
\hline & \multicolumn{2}{|c|}{$\begin{array}{l}\text { Optimal/ } \\
\text { adequate } \\
(n=172)\end{array}$} & \multicolumn{2}{|c|}{$\begin{array}{c}\text { Suboptimal/ } \\
\text { inappropriate } \\
(n=114)\end{array}$} & \multicolumn{2}{|c|}{$\begin{array}{l}\text { Overall } \\
(n=286)^{\dagger}\end{array}$} \\
\hline & $\mathbf{n}$ & $\%$ & $\mathbf{n}$ & $\%$ & $\mathbf{n}$ & $\%$ \\
\hline \multicolumn{7}{|l|}{ Age } \\
\hline$<6$ mos & 7 & 63.6 & 4 & 36.4 & 11 & 3.8 \\
\hline $6 \mathrm{mos}-23 \mathrm{mos}$ & 36 & 57.1 & 27 & 42.9 & 63 & 22.0 \\
\hline $24+\operatorname{mos}$ & 129 & 60.8 & 83 & 39.2 & 212 & 74.1 \\
\hline \multicolumn{7}{|l|}{ Sex } \\
\hline M & 100 & 60.2 & 66 & 39.8 & 166 & 58.0 \\
\hline $\mathrm{F}$ & 72 & 60.0 & 48 & 40.0 & 120 & 42.0 \\
\hline \multicolumn{7}{|l|}{ Symptoms present } \\
\hline Otalgia & 130 & 60.2 & 86 & 39.8 & 216 & 75.5 \\
\hline No otalgia documented & 42 & 60.0 & 28 & 40.0 & 70 & 24.5 \\
\hline Otorrhoea & 44 & 57.1 & 33 & 42.9 & 77 & 26.9 \\
\hline No otorrhoea documented & 128 & 61.2 & 81 & 38.8 & 209 & 73.1 \\
\hline Fever $>=38^{\circ} \mathrm{C}$ & 45 & 80.4 & 11 & 19.6 & 56 & 19.6 \\
\hline No fever documented & 127 & 55.2 & 103 & 44.8 & 230 & 80.4 \\
\hline $\begin{array}{l}\text { Any two or more of otalgia, } \\
\text { fever or otorrhea }\end{array}$ & 53 & 63.9 & 30 & 36.1 & 83 & 29.0 \\
\hline $\begin{array}{r}\text { Only one of: otalgia, fever, } \\
\text { otorrhea }\end{array}$ & 106 & 60.9 & 68 & 39.1 & 174 & 60.8 \\
\hline None of above & 13 & 44.8 & 16 & 55.2 & 29 & 10.1 \\
\hline \multicolumn{7}{|l|}{ Systemic features present } \\
\hline $\begin{array}{r}\text { Systemic }^{\wedge} \text { and one or } \\
\text { more symptoms }\end{array}$ & 38 & 70.4 & 16 & 29.6 & 54 & 18.9 \\
\hline $\begin{array}{r}\text { Systemic^ but no } \\
\text { symptoms }\end{array}$ & 3 & 37.5 & 5 & 62.5 & 8 & 2.8 \\
\hline $\begin{array}{r}\text { Not systemic but one or } \\
\text { more symptoms }\end{array}$ & 121 & 59.6 & 82 & 40.4 & 203 & 71.0 \\
\hline
\end{tabular}


Neither systemic nor symptoms present

\section{Tympanic membrane}

findings

$\begin{array}{rcccccc}\text { Redness } & 89 & 63.1 & 52 & 36.9 & 141 & 49.3 \\ \text { Bulging } & 40 & 59.7 & 27 & 40.3 & 67 & 23.4 \\ \text { Ruptured } & 16 & 53.3 & 14 & 46.7 & 30 & 10.5 \\ \text { air fluid level } & 6 & 54.5 & 5 & 45.5 & 11 & 3.8 \\ \text { Effusion } & 29 & 58.0 & 21 & 42.0 & 50 & 17.5 \\ \text { Any of above } & 117 & 58.5 & 83 & 41.5 & 200 & 69.9 \\ \begin{array}{r}\text { redness } \\ \text { rexcept }\end{array} & 70 & 56.5 & 54 & 43.5 & 124 & 43.4\end{array}$

\section{Triage category}

\begin{tabular}{|c|c|c|c|c|c|c|}
\hline \\
\hline 2 & 6 & 85.7 & 1 & 14.3 & 7 & 2.4 \\
\hline 3 & 121 & 62.7 & 72 & 37.3 & 193 & 67.5 \\
\hline $4 / 5$ & 45 & 52.3 & 41 & 47.7 & 86 & 30.1 \\
\hline \multicolumn{7}{|l|}{ Previous AOM } \\
\hline Yes & 38 & 56.7 & 29 & 43.3 & 67 & 23.4 \\
\hline No/Unknown & 134 & 61.2 & 85 & 38.8 & 219 & 76.6 \\
\hline \multicolumn{7}{|l|}{ Treating doctor level } \\
\hline Junior (intern or student) & 21 & 61.8 & 13 & 38.2 & 34 & 11.9 \\
\hline Resident & 59 & 66.3 & 30 & 33.7 & 89 & 31.1 \\
\hline Registrar & 73 & 54.1 & 62 & 45.9 & 135 & 47.2 \\
\hline Consultant & 17 & 68.0 & 8 & 32.0 & 25 & 8.7 \\
\hline Other/unknown & 2 & 66.7 & 1 & 33.3 & 3 & 1.0 \\
\hline \multicolumn{7}{|l|}{ Hospital } \\
\hline Robina & 53 & 74.6 & 18 & 25.4 & 71 & 24.8 \\
\hline University Hospital & 119 & 55.3 & 96 & 44.7 & 215 & 75.2 \\
\hline \multicolumn{7}{|c|}{ Watch and wait method used } \\
\hline Yes & 9 & 39.1 & 14 & 60.9 & 23 & 8.0 \\
\hline No & 161 & 61.9 & 99 & 38.1 & 260 & 90.9 \\
\hline Unknown & 2 & 66.7 & 1 & 33.3 & 3 & 1.0 \\
\hline
\end{tabular}

\section{Antibiotic use}




\begin{tabular}{|r|r|c|c|c|c|c} 
Yes & 96 & 53.0 & 85 & 47.0 & 181 & 63.3 \\
No & 76 & 72.4 & 29 & 27.6 & 105 & 36.7 \\
$\begin{array}{c}\text { Analgesia use } \\
\text { Paracetamol only }\end{array}$ & 30 & 66.7 & 15 & 33.3 & 45 & 15.7 \\
Ibuprofen only & 29 & 59.2 & 20 & 40.8 & 49 & 17.1 \\
Opioid only & 3 & 50.0 & 3 & 50.0 & 6 & 2.1 \\
$\begin{array}{c}\text { Combination of above } \\
\text { Any pain relief }\end{array}$ & 63 & 71.6 & 25 & 28.4 & 88 & 30.8 \\
No pain relief & 47 & 66.5 & 63 & 33.5 & 188 & 65.7 \\
Likelihood of acute otitis media condition \\
Likely & 53 & 71.6 & 21 & 28.4 & 74 & 25.9 \\
Possible & 100 & 56.8 & 76 & 43.2 & 176 & 61.5 \\
Unlikely & 19 & 52.8 & 17 & 47.2 & 36 & 12.6 \\
Represented within one week & & & & & \\
Yes & 8 & 57.1 & 6 & 42.9 & 14 & 4.9 \\
No & 164 & 60.3 & 108 & 39.7 & 272 & 95.1 \\
Exceeded 4 hours of stay & & & & & & \\
Yes & 21 & 72.4 & 8 & 27.6 & 29 & 10.1 \\
No & 151 & 54.7 & 106 & 38.4 & 257 & 89.9 \\
\hline
\end{tabular}

† Excludes 19 patients for whom antibiotic appropriateness could not be ascertained 
Figure 1: Flowchart of included patients and antibiotic prescription

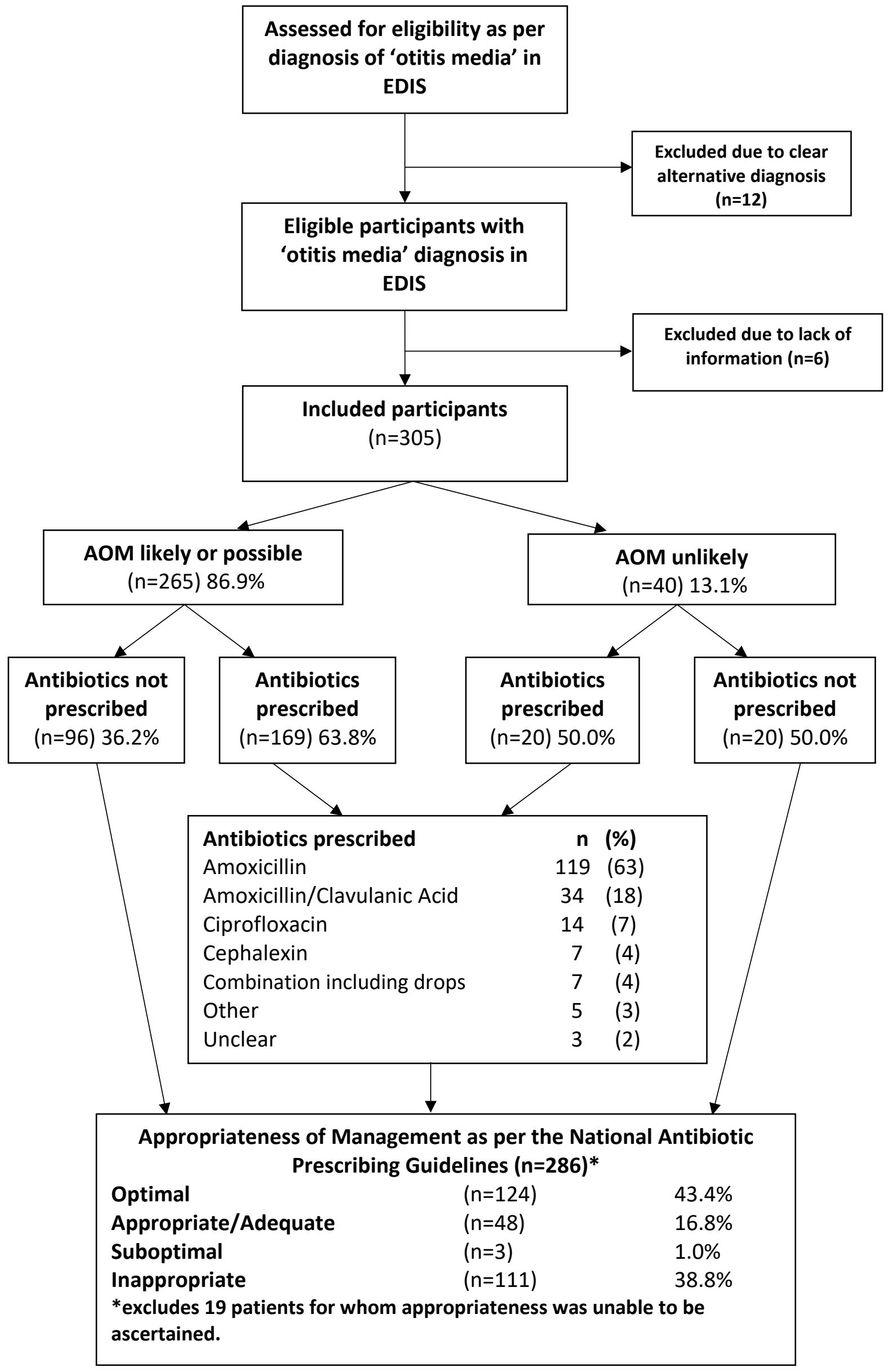

